\title{
Dual technology energy storage system applied to two complementary energy markets
}

\author{
Helder Lopes Ferreira*, Madeleine Gibescu*, Kateřina Staňková ${ }^{\dagger}$, Wil L. Kling*, Joao Peças Lopes ${ }^{\ddagger}, \S$ \\ *Eindhoven University of Technology, Den Dolech, 2, Eindhoven, The Netherlands \\ h.m.lopes.ferreira@tue.nl,m.gibescu@tue.nl,w.l.kling@tue.nl \\ ${ }^{\dagger}$ Department of Knowledge Engineering, Maastricht University, Bouillonstraat 8-10, Maastricht, The Netherlands, \\ k.stankova@maastrichtuniversity.nl \\ $\ddagger$ Electrical Engineering Department, University of Porto, Rua Dr. Roberto Frias, 378, Porto, Portugal, jpl@ fe.up.pt \\ $\S$ INESC Porto Institute for Systems and Computer Engineering of Porto, Portugal
}

\begin{abstract}
This paper deals with integrating energy storage systems (ESS) into existing electricity markets. We explain why ESS increase flexibility of power systems and energy markets and why more flexible systems and markets are desirable, particularly in a context of high integration of variable renewable energy sources (RES). The Dutch electricity markets are introduced as the case studies. As opposing to the existing literature, we focus on implementation of a dual technology ESS, which we believe is more beneficial than a single ESS. To show this, we introduce an optimal control model, in which the goal is to maximize the revenues of the dual technology energy storage system applied into two different energy markets, assuming the selling and buying electricity prices are exogenous. Subsequently, we introduce our model, using a simple strategy and present its results, showing the impact of the devices nominal rating on the potential revenues.
\end{abstract}

Keywords-Energy Storage Systems, Electricity Market, Imbalance Market, Renewable Energy Sources, Optimization

\section{INTRODUCTION AND LITERATURE REVIEW}

Worldwide sustainability-driven policy goals include further integration of the renewable generation technologies into energy markets. For example, the European Union is supposed to go beyond $20 \%$ of energy generated from renewable energy sources (RES) is 2020 and in 2030 to achieve a minimum of $27 \%$ of the renewable-generated energy [1]. Furthermore, the objectives for 2050 will be even more daunting with a reduction of the carbon emissions between $80 \%$ and $95 \%$ [2]. Not only in EU, but all around the world (e.g. in China [3], Japan [4], New Zealand [5], United States of America [6], [7], and Turkey [8]) the power systems are being prepared for the biggest renewable generation technology deployment ever seen.

Besides RES, also the integration of other novel technologies, such as electric vehicles (EV), as well as the unbundling and deregulation of the power sector all around the world, influence and change the paradigm and structure of the power sector. The integration of all these new technologies and changes calls for adjustment of planning and operation of the power systems; they need to be more flexible. This flexibility can be achieved through several technologies and techniques (e.g. energy storage systems (ESS), crossborder interconnection capacity, RES curtailment, flexible conventional generation, and demand-side management) and their combinations [9]. In recent years, many existing ESS (especially hydro-storage systems) and interconnections have been upgraded. However, even though the potential for PHES is still significant, it is not located near the demand centers [10] and in some countries the potential for building cost-effective sites is limited or non-existing (e.g., The Netherlands).

Energy storage can accomplish several services, which can be divided into two groups:
i. power market arbitrage
ii. ancillary services and balancing markets.

Power market arbitrage consists of storage devices charging in hours when electricity prices are low, and discharging in hours when prices are high [11]. These price variations are caused by daily, weekly or seasonal cycles. Lately, also variations from variable renewable power generation, e.g. wind and solar, are affecting the markets in a degree depending on their level of penetration and the flexibility of the underlying conventional generation fleet. The most adequate markets exercising arbitrage are day-ahead and intra-day markets.

As system operators are not allowed to own energy generation assets in an unbundled market, they need to procure ancillary services. These ancillary services include balancing support, congestion management and network investment deferral. This paper focuses on a combination of energy market arbitrage and provision of balancing support.

Nevertheless, other services are possible to be supplied by ESS. Several studies performed a comprehensive compilation of the potential services that energy storage may provide [6], [7], [11]. As shown in [11], different energy storage technologies have different characteristics that allow them to be more suitable for providing different services.

New storage technologies and energy management approaches (based on assumptions for the underlying energy markets) have been studied over the past years. Different types of models, problem formulations and solution techniques have been put into place, taking into account the interests of different stakeholders [12], [13]. The literature implies that in most markets, with current price differences, arbitrage may not be sufficient to make energy storage profitable. However, existing models only take one market and one ESS technology into consideration. Our hypothesis is that a system combining arbitrage and ancillary services will expectedly allow a higher level of revenues and thus a lower pay back time, than only arbitrage.

In this paper, we introduce a strategy for the application of the dual storage system in the markets, with the goal to minimize the storage system payoff time. Our case study is the 
Dutch energy market. As the initial step in finding the optimal strategy to use such a system, we consider a set of pre-specified simple strategies, and compare those strategies.

The rest of the paper is composed as follows. Section II presents the electricity markets of The Netherlands. Section III introduces the model, section IV the mathematical formulation and section $\mathrm{V}$ the implementation of the partial models and of the full model. Section VI presents the case studies. Section VII finalizes the paper with the conclusions.

\section{EleCTRICITY MARKETS OF THE NETHERLANDS}

In the Netherlands most part of the energy is still traded at bilateral level. In this bilateral market the generation companies sell the electricity directly to large consumers, traders or supply companies. The remaining energy is traded in the spot market. For the Dutch electricity market, there are two spot markets: the day-ahead and the intraday markets. For balancing purposes also exists a dedicated balancing market. The day-ahead and intraday markets have distinct dimensions. For 2011, about $40 \mathrm{TWh}$ of electricity were traded in the dayahead market and less than $1 \%$ of that value, $278 \mathrm{GWh}$ were traded in the intraday market [14].

\section{A. Day-ahead market}

The Dutch day-ahead market is active every day prior to the day of operation, until $12 \mathrm{~h}$. This market has a hourly time step.

\section{B. Balancing market}

Due to its specifications, we explain in more detail the functioning of the Dutch balancing market. This market works with a program time unit (PTU) of 15 minutes. Each balancing responsible party (BRP) aggregates a part of the consumers and of the generators in The Netherlands. These BRPs submit to the transmission system operator (TSO) plans of their expected net energy exchange with other BRPs. In real time, the TSO verifies if there is any imbalance on the system.

There are two types of BRPs, ones "which are specifically asked to provide balancing capacity by active contributions (Balancing Service Providers - BSPs) and the other BRPs that either use the imbalance settlement system for their own imbalance or that contribute without being actively selected by the bidding ladder" [15].

By bidding on the imbalance market, each BSP provides to the TSO the right, but not the obligation to buy balancing energy [15]. The contributions that can be considered in each PTU are for upwards, downwards and both upwards/downwards regulation. In Table I those balancing situations are described. Situation -1 means that there is an excess of power on the system; situation 1 indicates that there is a lack of power on the system; situation 2 is when, during the PTU of 15 minutes we have both periods of excess and lack of power; finally, situation 0 is when there is no imbalance.

\begin{tabular}{ccccc}
\hline $\begin{array}{c}\text { Balancing } \\
\text { Situation }\end{array}$ & -1 & 0 & 1 & 2 \\
\hline Condition & $\begin{array}{c}\text { Long } \\
\text { (surplus) }\end{array}$ & $\begin{array}{c}\text { No } \\
\text { Imbalance }\end{array}$ & Short & $\begin{array}{c}\text { Both long } \\
\text { and short }\end{array}$ \\
\hline
\end{tabular}

Table I. BALANCING Modes In The Netherlands, BASED ON [15]
As a way to incentivize active participation of the BRPs in the market, the payments due to these BRPs are decreased by a penalty by unit of energy. This penalty is calculated in a way to optimize the performance of the imbalance settlement system. However, most of the time this penalty is equal to zero [15].

Based on data from 2011, we calculated the average price of energy per MWh in The Netherlands. For the day-ahead market it is $52 € / \mathrm{MWh}$. For the balancing market, upward regulation it is $85 € / \mathrm{MWh}$ and downward regulation it is 21,31 $€ / \mathrm{MWh}$.

\section{MODEL DESCRIPTION}

In this section we will introduce our model of energy storage systems and its incorporation into two electricity energy markets. The energy storage system that we present is composed of two cooperating energy storage technologies, a bulk and a high power technology, trading in two different energy markets: the day-ahead and the balancing market. The markets selected are the ones of The Netherlands.

The model is built from a storage owner's point of view, whose goal is to minimize the payoff time of this dual system. The day-ahead market is used to perform energy price arbitrage. Furthermore, the storage system is dimensioned in such a way that it can also provide active contribution to the Dutch balancing market. The combination of technologies considered is a CAES (compressed-air energy storage) as a high-energy, long-term storage device, and a flywheel (FW) system as a high-power, low-energy device. Figure 1 depicts the relationship between the markets and the technologies. We have built two partial models, each of them describing the behavior of one of these technologies (see section $\mathrm{V}$ for details). Since the minimum bid size for the Dutch balancing market is $5 \mathrm{MW}$ [15], this value was selected as the minimum nominal power rating of the high power device.

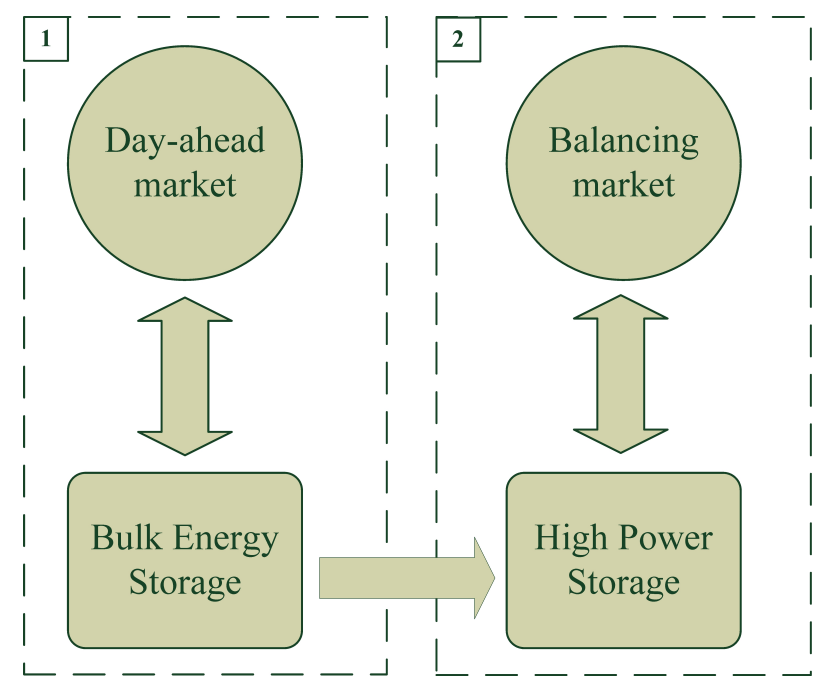

Figure 1. Illustration of the relationship among the markets and technologies The arrows indicate the direction of possible energy transfer. The numbers 1 and 2 indicate the partial models

In our model, we assume a perfect forecast and a price taker approach of the electricity prices. This is the most common method for the analysis of the potential revenues from energy storage. Takes the market as it is, not considering any eventual price impact of energy storage. This method has 
advantages in terms of simplicity of use and design. Price taker approach is based on two assumptions [16]:

- "The storage size is not big enough to modify market prices;"

- "A perfect forecast window, more or less extended according to the study."

This approach was adopted since the size of the energy storage device is small compared to the size of the market and thus the installation is marginal and "does not exert any influence on the price level" [16]. Literature suggests that this approach overestimates the economic benefits of the devices, but at least " $80 \%$ of the value with long term perfect forecast could realistically be gained with real operational strategies" [13].

The second assumption (perfect forecast) has been analyzed by several authors and the general view is that it conducts to an overestimation of the economic benefits. Some authors have performed sensitivity analysis, such as [12], [13], [17]. Among their conclusions was that "around $80 \%$ of the value with long term perfect forecast could realistically be gained with real operational strategies" [12]. This value can be improved depending on the approximation used, and can be improved significantly by using simple forecasting techniques [17]. Nonetheless, perfect forecast can be a real and practical approach when "the market operator perform a centralized optimization to decide the optimal allocation of storage resources over the time and among different actors" [18]. This could only be feasible in a very well regulated market. Among the limitations of this approach comes from the energy market price volatility derived from the integration of renewable energy sources. Nonetheless, some authors go deeper in these studies, and analyze the simultaneous provision of both reserve services and arbitrage. Among these authors one my find [19], [20]. However, these analysis may also overestimate the value of storage, as the interactions between providing arbitrage and reserve services are not fully studied yet [19].

Compressed air energy storage (CAES) technology was selected as the bulk technology due to the geology of The Netherlands. CAES systems could be built using existing underground salt deposits or the depleted gas deposits in the north of The Netherlands. For the role of high power device several options exist from different chemical batteries including flow batteries up to fly wheels. In this example, we have used fly wheels.

\section{Mathematical Formulation}

From a set of initial strategies we have selected the one described in this section. Our goal is to find the optimal charge and discharge price boundaries per device type and day, so that the revenues are maximized. For the sake of simplicity of the formulation, we assume that each device has a unique type and that each type identifies uniquely the type of market it is used for. Mathematically speaking, the problem of finding the optimal strategy for the energy storage device system, composed of the finite set $J$ of storage devices, can be formulated as an optimal control problem. We will first formulate this problem without taking into account the transfer of electricity among the storage devices:
Find

$$
u^{*}=\arg \max _{u \in U} \sum_{j \in J} \sum_{\delta=1}^{|D|} \sum_{t=1}^{\left|T_{j}\right|}\left(q_{D}^{j, \delta, t} \cdot \eta_{D}^{j} \cdot p_{S}^{j, \delta, t}-q_{C}^{j, \delta, t} \cdot \frac{p_{B}^{j, \delta, t}}{\eta_{C}^{j}}\right)
$$

with

$$
\begin{aligned}
& u=\left(h_{B}^{1}, h_{S}^{1}, \ldots, h_{B}^{|J|}, h_{S}^{|J|}\right) \\
& \pi_{B}^{j, \delta}=\frac{\sum_{1}^{\left|T_{j}\right|} p_{B}^{j, \delta, t}}{\left|T_{j}\right|} \cdot\left(1-h_{B}^{j}\right), \quad \pi_{S}^{j, \delta}=\frac{\sum_{1}^{\left|T_{j}\right|} p_{S}^{j, \delta, t}}{\left|T_{j}\right|} \cdot\left(1+h_{S}^{j}\right) \\
& q_{B}=\frac{q_{C}^{j, \delta, t}}{\eta_{C}^{j}}, \quad q_{S}=q_{D}^{j, \delta, t} \cdot \eta_{D}^{j} \\
& z_{C}^{j, \delta, t}=x_{C}^{j, \delta, t-1}+q_{C}^{j, \delta, t}-q_{D}^{j, \delta, t} \quad \text { with } \\
& x_{C}^{j, \delta, t}=\left\{\begin{array}{l}
z_{C}^{j, \delta, t}, \quad \text { if } \quad z_{C}^{j, \delta, t} \in\left[x_{C, \min }^{j}, x_{C, \max }^{j}\right] \\
x_{C, \min }^{j, \delta, t} \quad \text { if } \quad x_{C}^{j, \delta, t}<x_{C, \min }^{j} \\
x_{C, \max }^{j, \delta,}, \quad \text { if } \quad x_{C}^{j, \delta, t}>x_{C, \max }^{j}
\end{array}\right. \\
& q_{D}^{j, \delta, t}=\left\{\begin{array}{l}
x_{C}^{j, \delta, t-1}-x_{C, \min }^{j, \delta, t}, \quad \text { if } \quad p_{S}^{j, \delta, t} \geq \pi_{S}^{j, \delta} \\
0, \quad \text { elsewhere }
\end{array}\right. \\
& q_{C}^{j, \delta, t}=\left\{\begin{array}{cc}
x_{C, \max }^{j, \delta, t}-x_{C}^{j, \delta, t-1}, & \text { if } p_{B}^{j, \delta, t} \leq \pi_{B}^{j, \delta} \\
0, & \text { elsewhere }
\end{array}\right.
\end{aligned}
$$

Here $J$ is the set of types of energy storage devices in use, assuming that each type is used at a different market, uniquely defined by the device type. $p_{B}^{j, \delta}$ denotes a buying price threshold for type of device and market $j$. If the current price of electricity $p^{j, \delta, t}$ for electricity storage type and market $j$, day $\delta$, and time interval $t$ within the day, is less or equal the buying price threshold $p_{B}^{j, \delta}$, we will charge device $j$ to its full capacity. Similarly, if $p^{j, \delta, t} \geq p_{S}^{j, \delta}$, where $p_{S}^{j, \delta}$ denotes the selling price threshold for device type and market $j$, the device will discharge at the maximum power rating. The prices for buying and selling are calculated based on the daily price average using thresholds $h_{B}^{j}$ and $h_{S}^{j}$. Both $h_{B}^{j} \in[0,0.5]$ and $h_{S}^{j} \in[0,0.5]$ are applied in equations 3 to calculate the daily threshold charging prices and selling prices, respectivelly. These thresholds are simetrical, and when they are set to 0 it corresponds to the average daily price. Parameter $|D|$ represents the number of days being analyzed and $T_{j}$ the time periods per day in an hourly market for an average day, this will be 24 hours.

Variables $q_{C}^{j, \delta, t}$ and $q_{D}^{j, \delta, t}$ indicate the quantity of electricity charge and discharged at market $j$, day $\delta$, and time interval $t$. Parameters $\eta_{D}^{j} \in[0,1]$ and $\eta_{C}^{j} \in[0,1]$ define efficiency of discharging and efficiency of charging, respectively, and are known a priori. Variables $q_{B}^{j, \delta, t}$ and $q_{S}^{j, \delta, t}$ are related with variable $q_{C}^{j, \delta, t}$ and $q_{D}^{j, \delta, t}$ trough $q_{C}^{j, \delta, t}$ and $q_{D}^{j, \delta, t}$ as explained in equations 4. Parameter $x_{C}^{j, \delta, t}$ denote the state of charge of device $j$, day $\delta$ and time interval $t . z_{C}^{j, \delta, t}$ indicates a possible state of charge between the minimum and the maximum possible states.

Therefore, the possible $u$ must satisfy these and select 
the thresholds $h_{B}^{j}$ and $h_{S}^{j}$ that allow the maximization of the revenues.

Thus, in words, the general problem (1), subject to (2)(7), is to find selling and buying threshold prices per day in a week, for each device type/market, so that the payoff time of the entire storage system device is minimized.

This method presents a simple but effective strategy that could be put into practice by a storage owner. It is based on the presupposition that the thresholds presenting the best results for an enough large period (e.g., a year or several years) could be an effective proxy to an equivalent or smaller period of time (e.g., a year).

\section{IMPLEMENTATION}

We start by describing the partial models which are the basis of the full model. In Figure 1 the bulk energy storage model is identified as model 1 and the high power model was identified as model 2. The technical and economical data on the devices was taken from [10]. All the case studies were implemented using Matlab.

1) Bulk energy storage model: The partial model uses a bulk energy storage device that provides energy arbitrage services to the day-ahead market. The device selected is a generic device based on a CAES. The CAES has a power rating of $100 \mathrm{MW}$ for a nominal discharge duration of 8 hours, providing thus an energy rating of $800 \mathrm{MWh}$. The data and timeline used in the case studies presented are the same: APX-Endex data on the Dutch market from 21/09/2011 to $31 / 12 / 2011$.

2) High power model: This partial model uses a fly wheel that charges and discharges from and to the balancing market. Whenever the charging price $p_{B}^{j, \psi}$ from the balancing market is higher than the cost of charging from a bulk energy device, it will charge from that external source. Following the algorithms described before, it will look for the a price higher $p_{S}^{j, \psi}$ than the minimum cost to sell.

If the market is idle ( balancing situation 0) and the ESS is not fully charged, the device will charge from the external bulk energy device. The cost of this charging charge is a value calculated using the CAES in the conditions described in Subsection V-1 and it is 30 euro per MW/h. For this calculation we have also considered the efficiencies of discharging and charging of both the CAES and the FW.

As an exercise we evaluated four strategies differentiated by which actions are allowed on the balancing market on situation 2 (buying, net sum of buying and selling, selling, sum of buying and selling). The results of this evaluation are shown in VI.

\section{A. Full model}

We have merged the two partial models, implementing a full model and optimized it using particle swarm optimization (PSO). We have used the PSO implementation by Haupt and Haupt [21]. In order to compare the results we have implemented 9 possibilities and we studied the influence of the sizing of the devices. In table II are shown the possibilities analyzed in our model.

We have observed that the result improvement after 25 iterations was usually reduced, thus we have run all the 9 possibilities during such an amount of iterations (25).

\begin{tabular}{|c|c|c|c|c|}
\hline Number & $\begin{array}{l}\text { CAES } \\
\text { power } \\
\text { rating } \\
(\mathrm{MW}) \\
\end{array}$ & $\begin{array}{c}\text { CAES } \\
\text { discharge } \\
\text { duration } \\
\text { (h) }\end{array}$ & $\begin{array}{l}\mathrm{FW} \\
\text { power } \\
\text { rating } \\
(\mathrm{MW}) \\
\end{array}$ & $\begin{array}{c}\text { FW } \\
\text { discharge } \\
\text { duration } \\
\text { (h) }\end{array}$ \\
\hline 1 & 100 & 10 & 20 & 0,25 \\
\hline 2 & 100 & 10 & 40 & 0,25 \\
\hline 3 & 100 & 10 & 80 & 0,25 \\
\hline 4 & 100 & 5 & 20 & 0,25 \\
\hline 5 & 100 & 5 & 40 & 0,25 \\
\hline 6 & 100 & 5 & 80 & 0,25 \\
\hline 7 & 50 & 5 & 20 & 0,25 \\
\hline 8 & 50 & 5 & 40 & 0,25 \\
\hline 9 & 50 & 5 & 80 & 0,25 \\
\hline
\end{tabular}

\section{CASE STUDIES RESUlTS}

\section{A. Bulk energy storage model}

We have extensively analyzed the function. In Figure 2, is shown a zoom to the optimum area of the payoff time function calculated for this partial model.

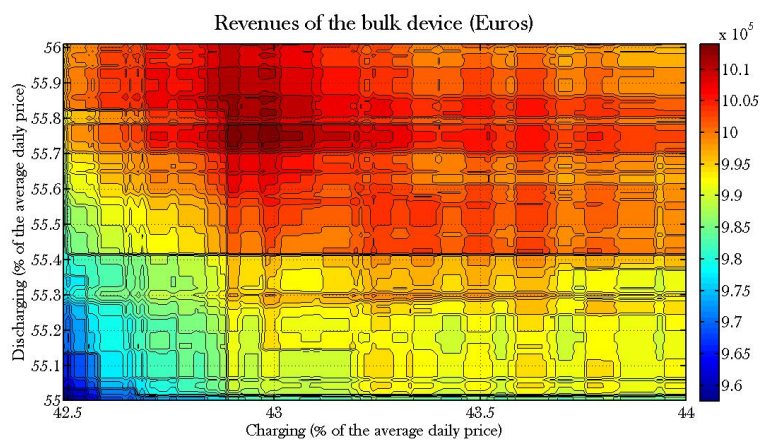

Figure 2. Revenues of the bulk device: zoom to the optimal area considering as reference the average daily price. Calculated optimum is at the point $(42.97$, 55.74).

\section{B. High power model}

For this model a flywheel (FW) with the minimum size of 20MW, with a discharge duration of 15 min (time unit of the Dutch balancing market), having thus $5 \mathrm{MWh}$ of energy rating, was selected. The data used was Dutch day-ahead market from 2009 to 2011. The charging and discharging efficiencies are $95 \%$. No self-discharge was considered as the device is working almost continuously.

We implemented the four strategies described in Subsection V-2 and their outputs are shown in Table III. As in The Netherlands, only one action for the BRPs is allowed per PTU [15], in this case the best algorithm is HP3.

\section{Full model}

In figure 3 it is possible to analyze the results of our model. Examining those results we conclude that the impact of the energy capacity of the high power device (FW) is higher than the impact of the bulk energy device (CAES). This is probably due to the higher value of the energy per MWh in the balancing market. In order to fully compare the profitability the costs of 


\begin{tabular}{cccc}
\hline Algorithm & $\begin{array}{c}\text { Strategy } \\
\text { in mode 2 }\end{array}$ & $\begin{array}{c}\text { Revenues } \\
\text { with min SoC } \\
\text { of } 10 \% \\
\text { (Euros) }\end{array}$ & $\begin{array}{c}\text { Revenues } \\
\text { using full } \\
\text { capacity } \\
\text { (Euros) }\end{array}$ \\
\hline HP1 & $\begin{array}{c}\text { Buy } \\
\text { (as in -1) }\end{array}$ & $6,8 \cdot 10^{6}$ & $6,2 \cdot 10^{6}$ \\
HP2 & $\begin{array}{c}\text { Net sum of buying } \\
\text { and selling }\end{array}$ & $7,6 \cdot 10^{6}$ & $6,9 \cdot 10^{6}$ \\
HP3 & $\begin{array}{c}\text { Sell (as in 1) } \\
\text { HP4 }\end{array}$ & $\begin{array}{c}\text { Sum of buying } \\
\text { and selling }\end{array}$ & $4,3 \cdot 10^{6}$ \\
Table III. & OUTPUT OF THE HIGH POWER DEVICE-RELATED \\
& $\quad$ ALGORITHMS
\end{tabular}

the device would have to taken in consideration. However, such comparison goes out of the scope of this paper.

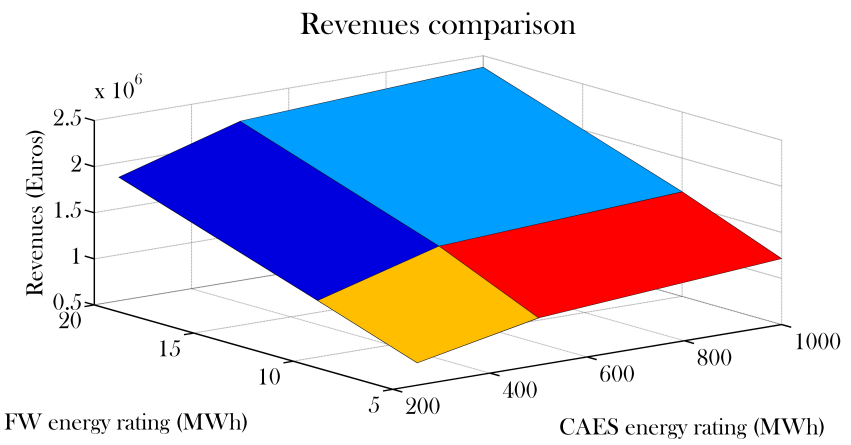

Figure 3. Comparison of the revenues of the full model

\section{CONCLUSIONS}

In this paper we have highlighted the importance of power grid flexibility in the present and in a future with a high level of penetration of renewable energy sources. Furthermore, we presented the role that ESS may play on such an evolution. We presented a novel model of an ESS using two different technologies with different characteristics trading simultaneously in two energy markets.

Our model and its application results to the markets of The Netherlands show that such a solution presents a level of revenues that depends of the size of the devices. For this case study, the impact of the nominal power and energy ratings of the high power device is higher than the ones of the bulk energy device.

In our future research, we intend to analyze the impact of having different sets of thresholds for each day of the week, instead of the single set implemented, and also to evaluate other possible strategies.

\section{ACNOWLEDGEMENTS}

The authors gratefully acknowledge the Amsterdam Power eXchange (APX) who provided the energy market data that has been used in this paper.

\section{REFERENCES}

[1] European Commission, COM/2013/0169 final - GREEN PAPER A 2030 framework for climate and energy policies, 2013.

[2] European Commission, COM(2011) 112 final - A Roadmap for moving to a competitive low carbon economy in 2050, 2011.

[3] Z. Ming, Z. Kun, and L. Daoxin, Overall review of pumped-hydro energy storage in China: Status quo, operation mechanism and policy barriers, Renew. Sustain. Energy Rev., vol. 17, pp. 3543, Jan. 2013.

[4] M. Esteban and J. Portugal-Pereira, Post-disaster resilience of a 100\% renewable energy system in Japan, Energy, vol. 68, pp. 756764, Apr. 2014.

[5] I. G. Mason, S. C. Page, and a. G. Williamson, Security of supply, energy spillage control and peaking options within a $100 \%$ renewable electricity system for New Zealand, Energy Policy, vol. 60, pp. 324333, Sep. 2013.

[6] Sandia National Laboratories, Energy Storage for the Electricity Grid: Benefits and Market Potential Assessment Guide, 2010.

[7] EPRI, Electricity Energy Storage Technology Options - A White Paper Primer on Applications, Costs and Benefits, 2010.

[8] B. Dursun and B. Alboyaci, The contribution of wind-hydro pumped storage systems in meeting Turkeys electric energy demand, Renew. Sustain. Energy Rev., vol. 14, no. 7, pp. 19791988, Sep. 2010.

[9] G. Papaefthymiou, K. Grave, and K. Dragoon, Flexibility options in electricity systems, Ecofys, European Copper Institute, 2014.

[10] IRENA, "Hydropower", IRENA Working Paper, Renewables Energy Technologies: Cost Analysis Series, vol. 1: Power Sector, Issue 3/5, June 2012.

[11] H. L. Ferreira, R. Garde, G. Fulli, W. Kling, and J. P. Lopes, Characterisation of electrical energy storage technologies, Energy, vol. 53, pp. 288298, 2013.

[12] G. N. Bathurst and G. Strbac, Value of combining energy storage and wind in short-term energy and balancing markets, Electr. Power Syst. Res., vol. 67, no. 1, pp. 18, Oct. 2003.

[13] A. Zucker, T. Hinchliffe, and A. Spisto, Assessing Storage Value in Electricity Markets A literature review. JRC Scientific and Policy reports, 2013.

[14] http://www.commodities-now.com/reports/general/9619-apx-endex2011-review.html, accessed 08-02-1015

[15] J. Frunt, Analysis of balancing requirements in future sustainable and reliable power systems, Technische Universiteit Eindhoven, 2011.

[16] C.K. Ekman, S.H. Jensen, Prospects for large scale electricity storage in Denmark, Energy Convers. Manag. 51 (2010) 11401147. doi:10.1016/j.enconman.2009.12.023.

[17] R. Sioshansi, P. Denholm, T. Jenkin, J. Weiss, Estimating the value of electricity storage in PJM: Arbitrage and some welfare effects, Energy Econ. 31 (2009) 269277. doi:10.1016/j.eneco.2008.10.005.

[18] X. He, E. Delarue, W.D. Haeseleer, J.-M. Glachant, Coupling electricity storage with electricity markets: a welfare analysis in the French market, 2012 .

[19] R. Deb, Operation hydroelectric plants and pumped storage units in a competitive environment, Electr. J. 6190 (2000) 2432.

[20] X. He, R. Lecomte, A. Nekrassov, E. Delarue, E. Mercier, Compressed Air Energy Storage multi-stream value assessment on the French energy market, in: PowerTech, 2011: pp. 16.

[21] R. L. Haupt, S. E. Haupt, Practical Genetic Algorithms, John Wiley \& Sons, Inc., 2004 